Portland State University

PDXScholar

May 7th, 11:00 AM - 1:00 PM

\title{
Development of a Design Guideline for Pile Foundations Subjected to Liquefaction-Induced Lateral Spreading
}

Milad Souri

Portland State University

Arash Khosravifar

Portland State University

Follow this and additional works at: https://pdxscholar.library.pdx.edu/studentsymposium

Part of the Computer Sciences Commons, and the Engineering Commons

Let us know how access to this document benefits you.

Souri, Milad and Khosravifar, Arash, "Development of a Design Guideline for Pile Foundations Subjected to Liquefaction-Induced Lateral Spreading" (2019). Student Research Symposium. 7.

https://pdxscholar.library.pdx.edu/studentsymposium/2019/Posters/7

This Poster is brought to you for free and open access. It has been accepted for inclusion in Student Research Symposium by an authorized administrator of PDXScholar. Please contact us if we can make this document more accessible: pdxscholar@pdx.edu. 
\& Portland $\underset{\text { SNIVRSITY }}{\text { State }}$

Maseeh College of Engineering and Computer Science

\section{Development of a Design Guideline for Pile Foundations}

Subjected to Liquefaction-Induced Lateral Spreading Milad Souri, PhD Candidate (Expected Graduation 2020)

Advisor: Dr. Arash Khosravifar

\section{Problem Statement}

Past earthquakes

confirmed that seismically-

induced kinematic loads

from soil lateral spreading

and inertial loads from

structure can cause severe

damages to pile

foundations. The research

questions are:

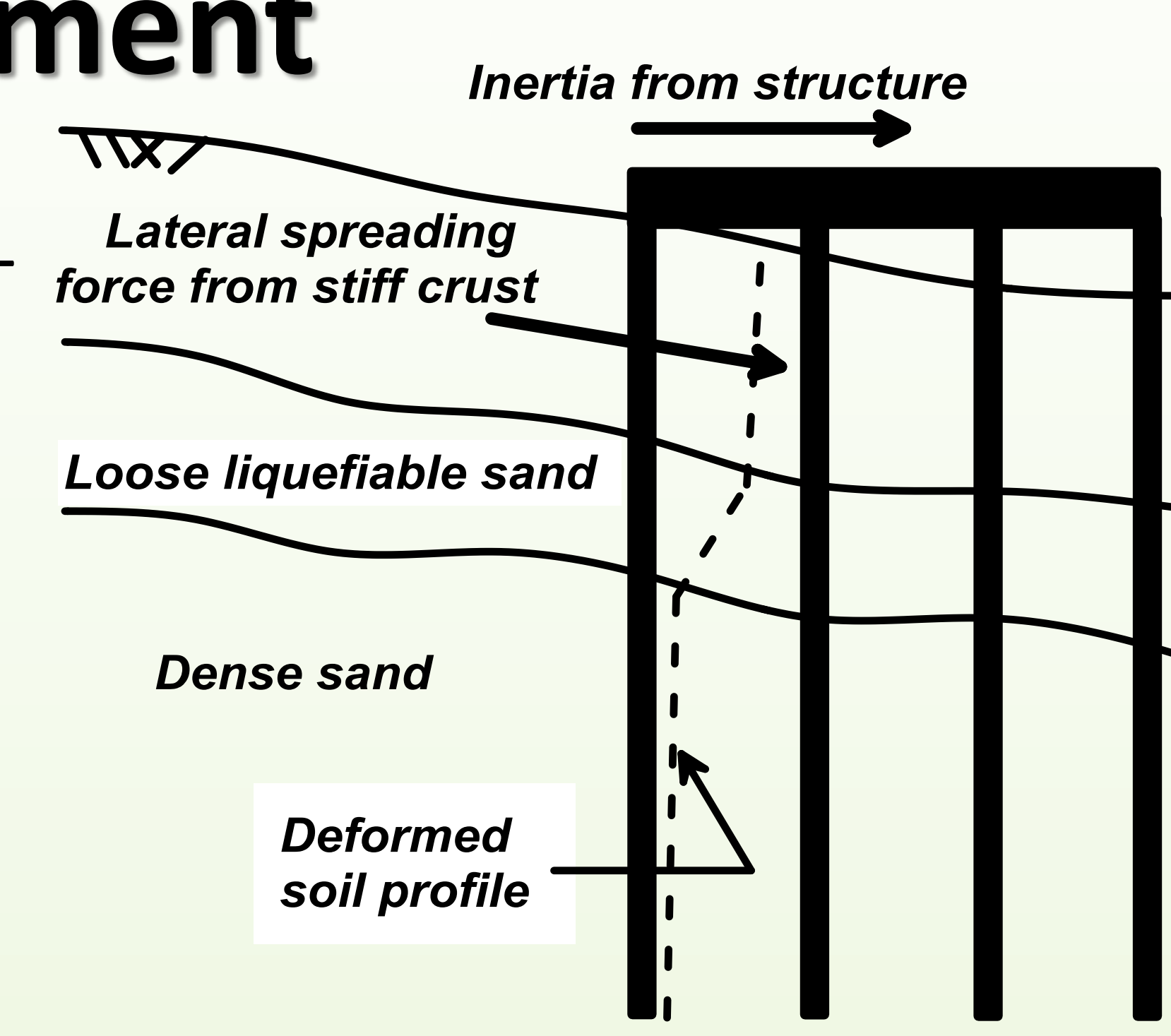

How to combine inertial and kinematic loads in design of pile foundations in liquefied soil?

> How the combination of inertia and kinematics changes with depth?

$>$ How this combination is affected by long-duration earthquakes?

$>$ How this combination affects inelastic demands in piles?

\section{Background}

Current design Design code Kinematic $\quad$ Inertial codes provide

varying

recommendations

on the

combination of

inertia and

kinematics.

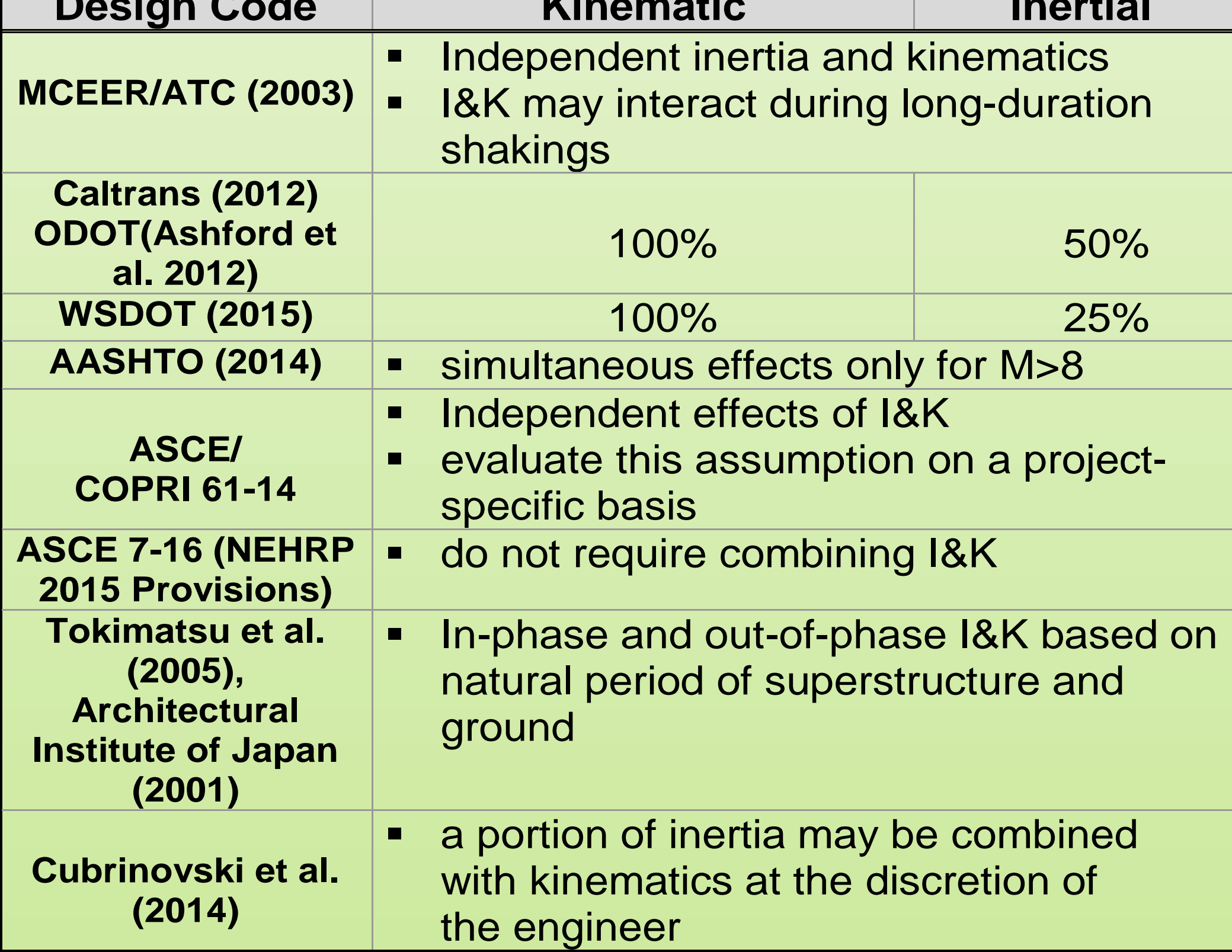

\section{Centrifuge Model}

Five centrifuge tests were performed on pile-supported wharves in liquefied soils by Dickenson, McCullough and Schlechter, using the geotechnical centrifuge at UC Davis. (McCullough et al. 2001)

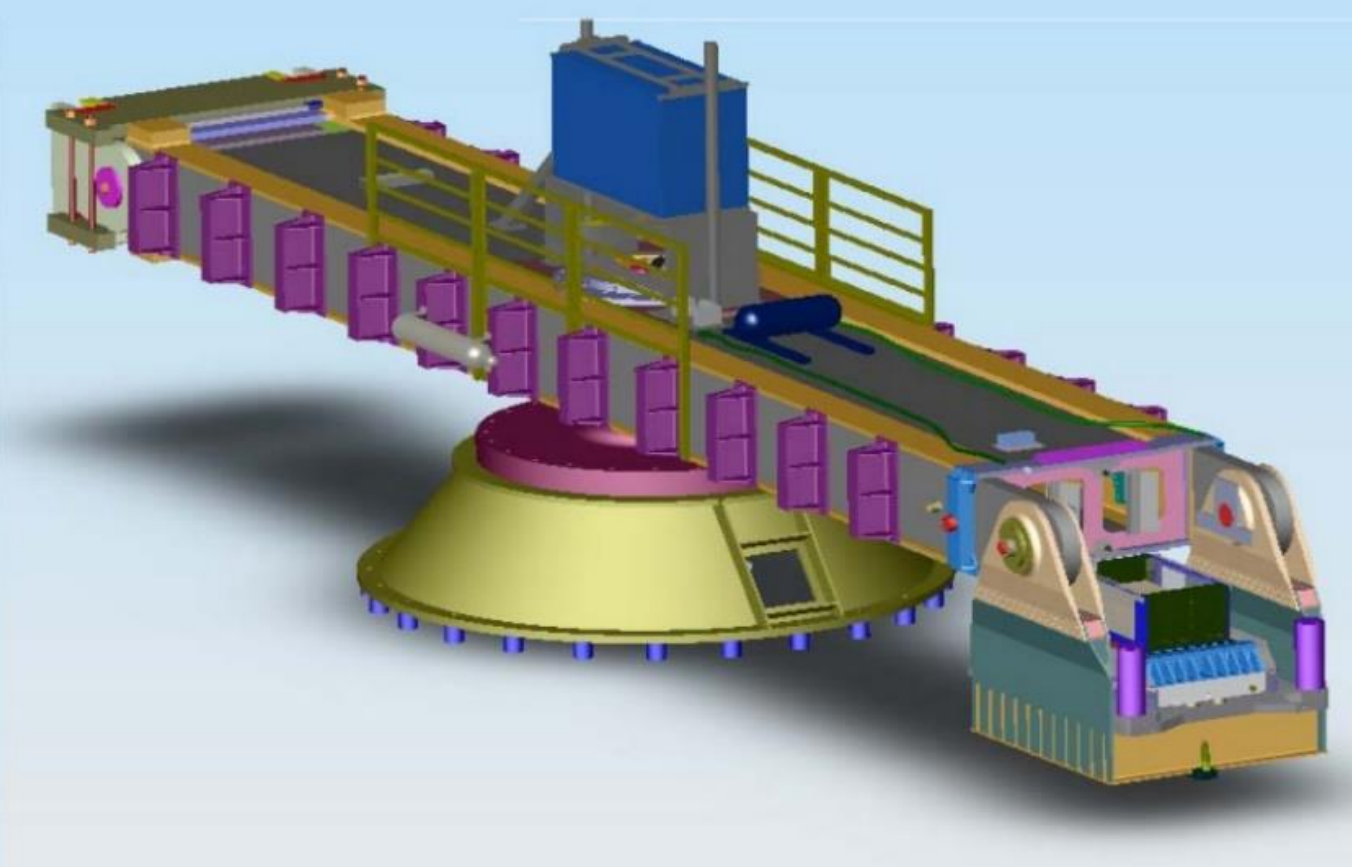

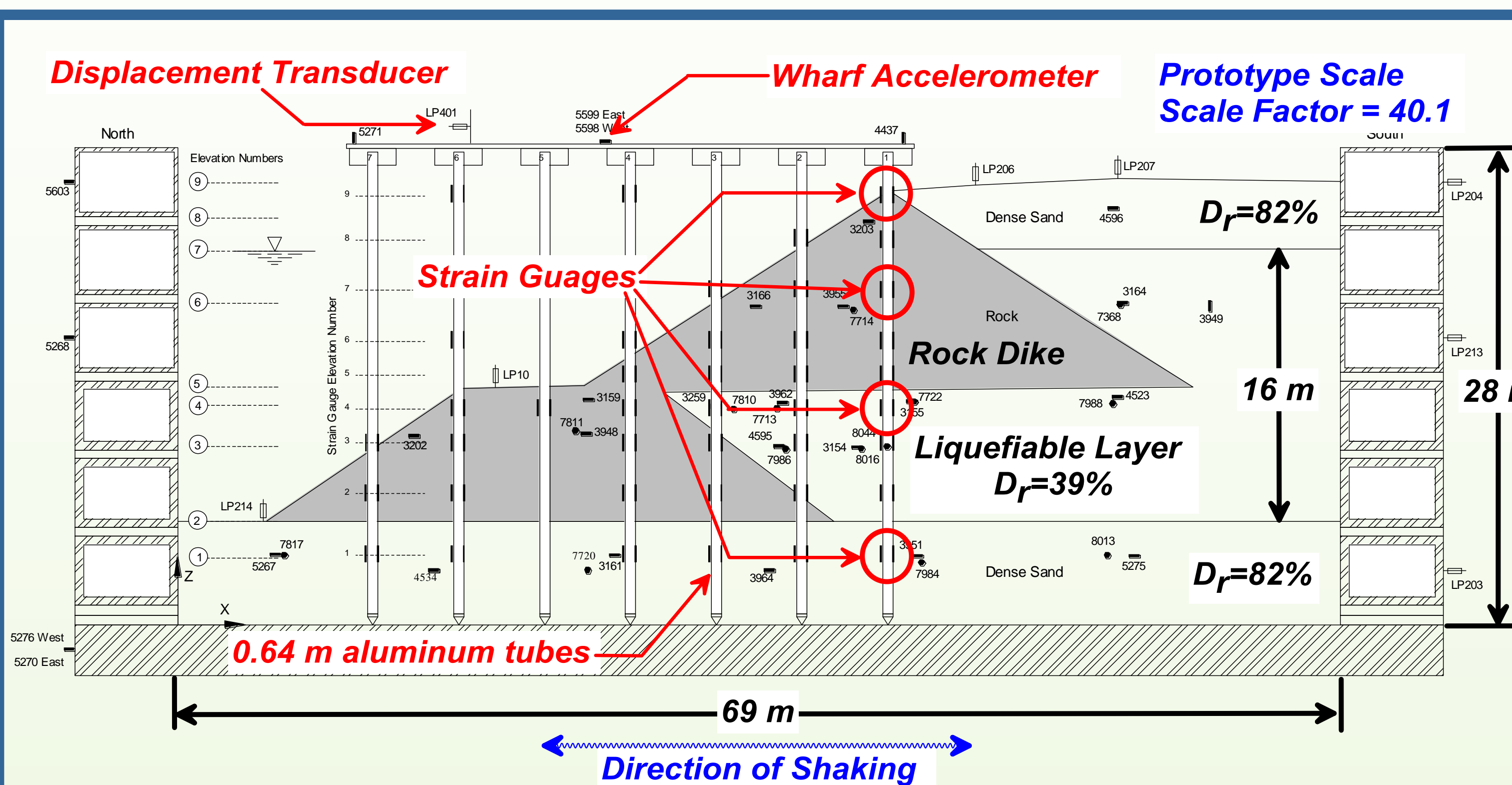

Representative cross section of centrifuge model (NJM01)

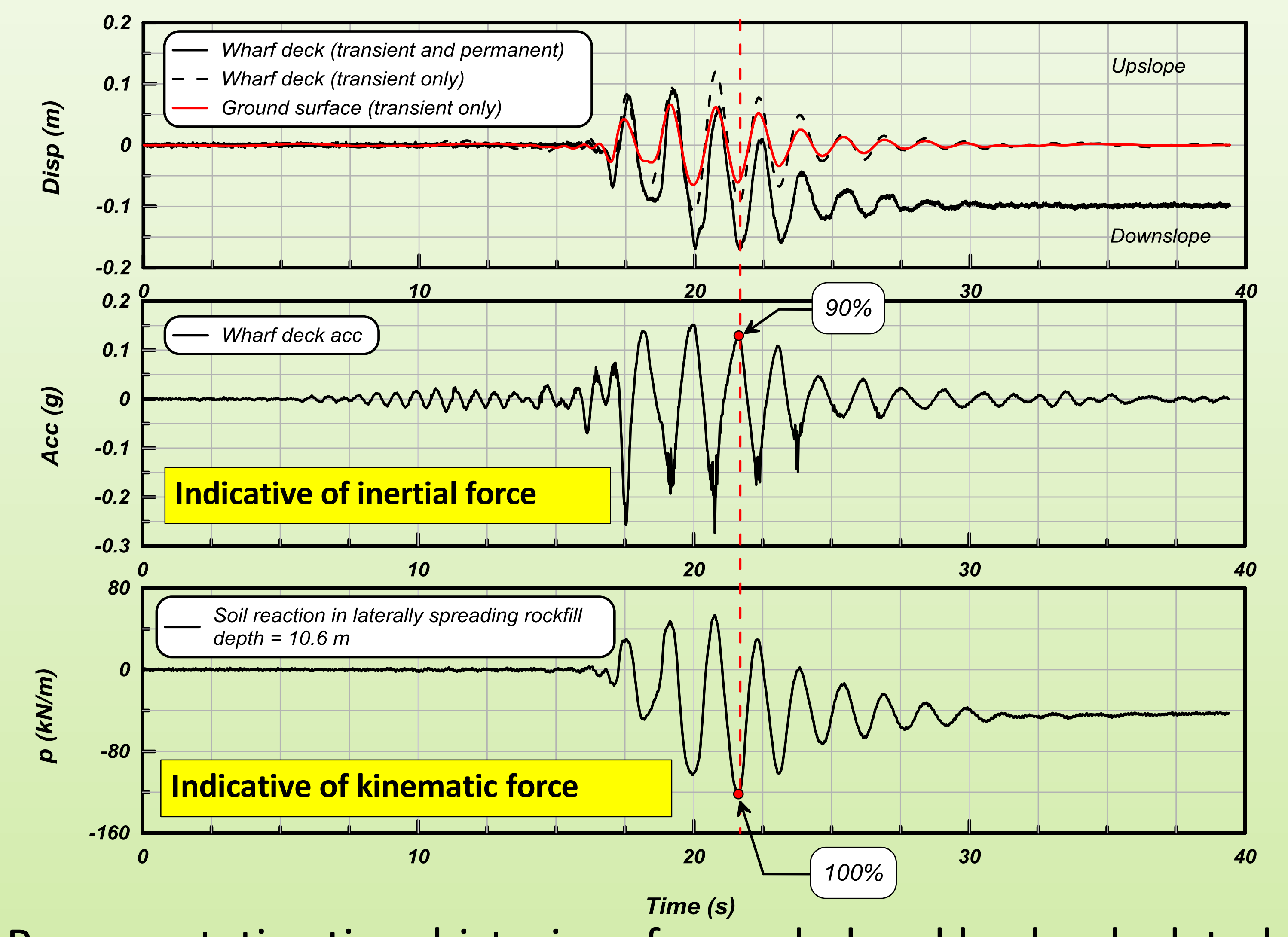

Representative time histories of recorded and back calculated data showed that both inertia and kinematic are close to $100 \%$.

\section{Pseudo-static Analysis}

The $p-y$ models performed in LPILE were subjected to three loading conditions to investigate the various load combinations in estimating the large bending moments that developed at the pile head and at deep locations along the piles.
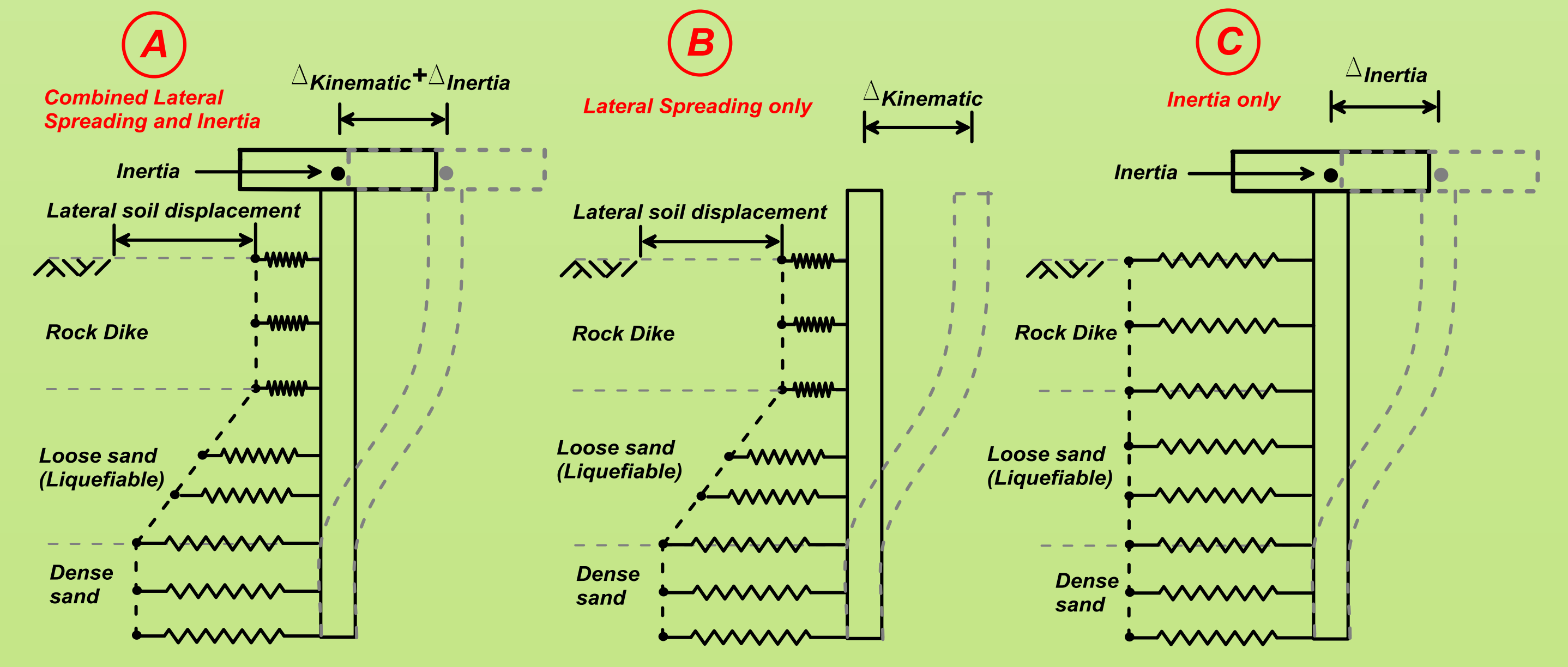

Interaction of Inertia and Kinematic

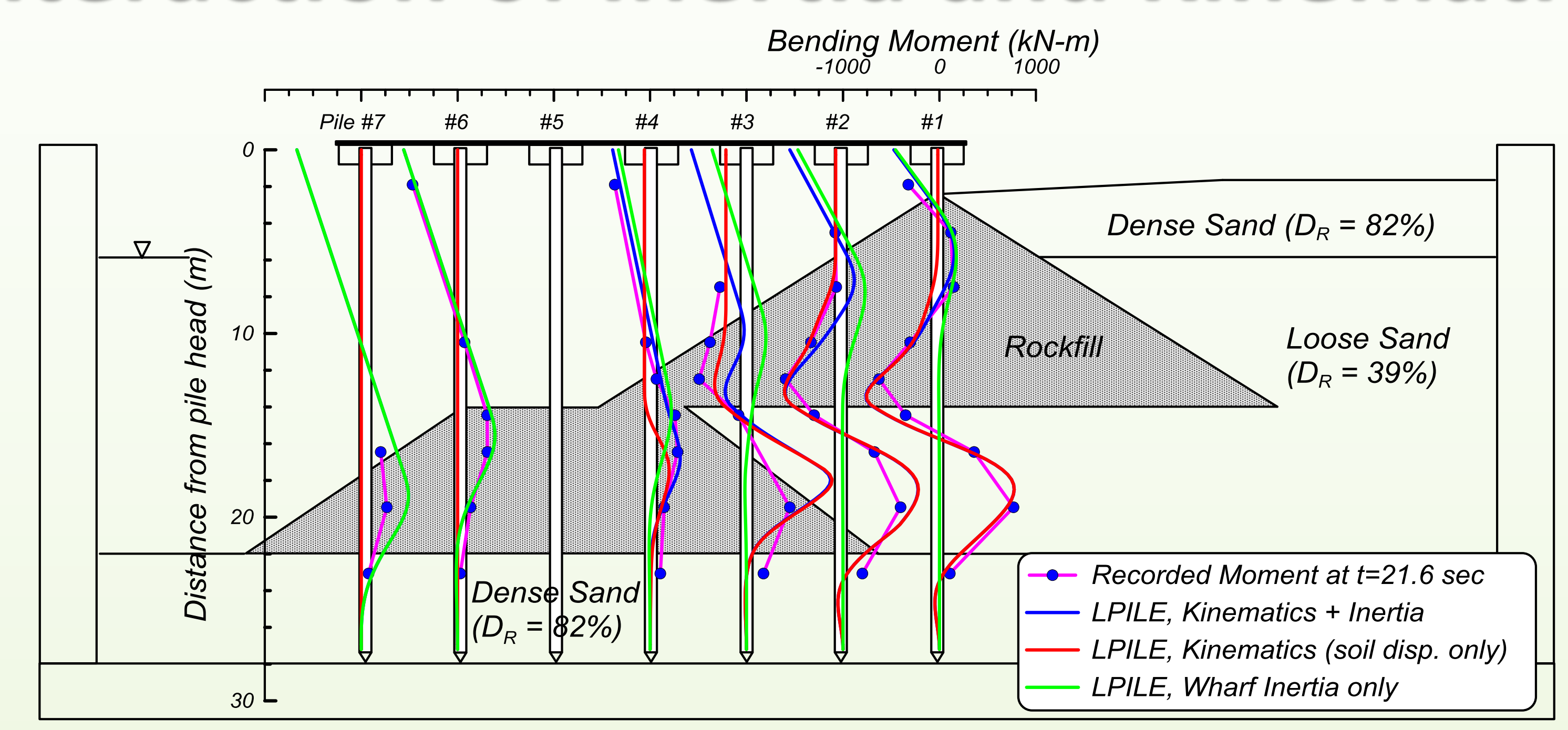

Inertia and kinematic fully interact at pile head and shallow depths, and that combined loads should be considered in design.

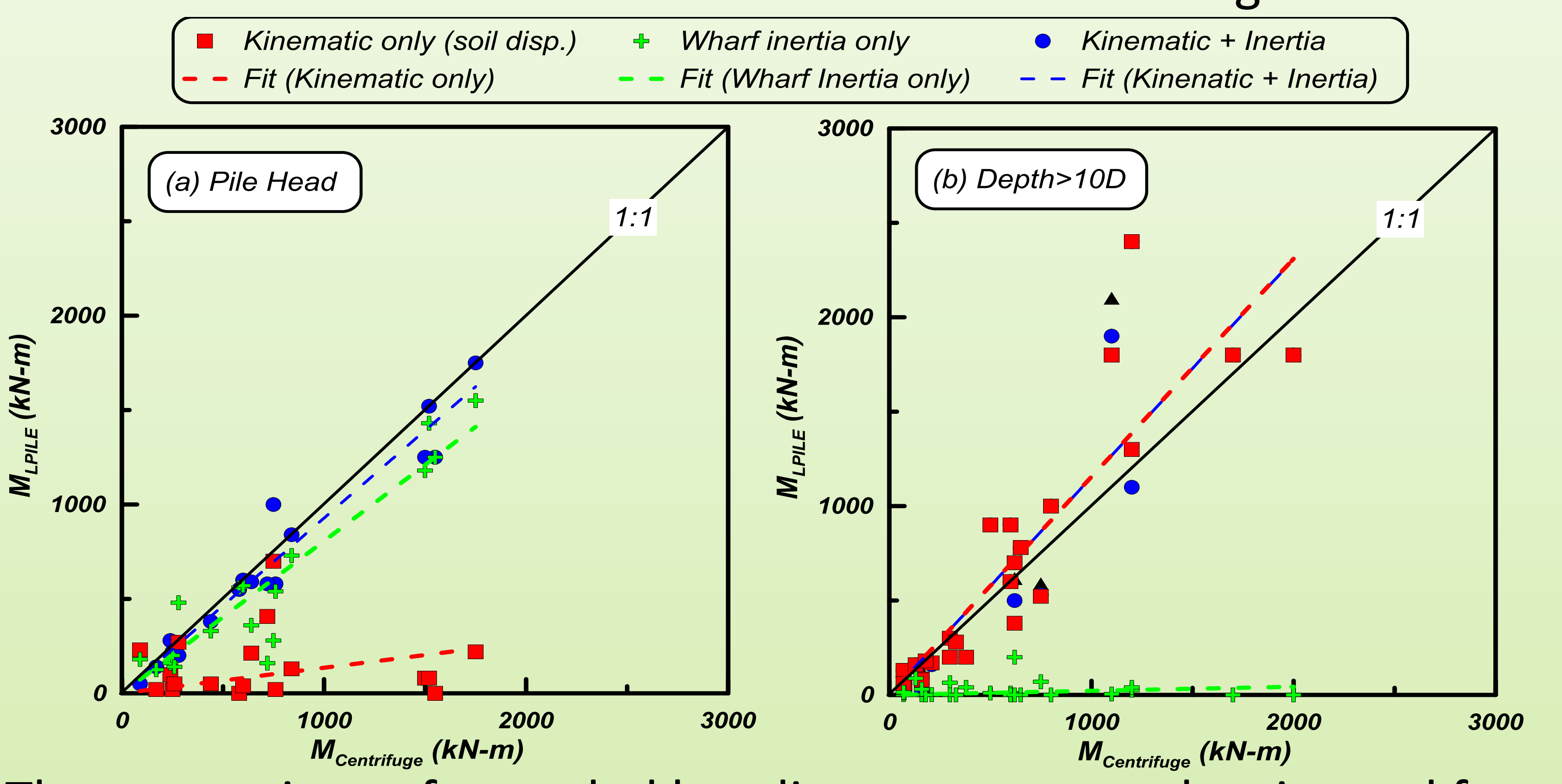

The comparison of recorded bending moments and estimated from LPILE in all five centrifuge tests, proposed below load combinations to estimate bending moments at different depths

\begin{tabular}{|ll|}
\hline $\begin{array}{l}\text { Location of maximum bending } \\
\text { moment }\end{array}$ & $\begin{array}{l}\text { Proposed load combination to be } \\
\text { considered in design }\end{array}$ \\
\hline Pile head & $100 \%$ Kinematics $+100 \%$ Inertia \\
\hline Deep locations (>10D) & $100 \%$ Kinematics + 0\% Inertia \\
\hline
\end{tabular}

\section{Future Works}

$>$ Perform numerical analysis in FLAC2D and validate against centrifuge data

- Evaluate the effects of long duration earthquakes and piles inelasticity on the combination of inertial and kinematic demands Propose design guidelines for piles in liquefied soils

\section{Acknowledgement}

The authors would like to acknowledge Dr. Steve

McCullough (Jacobs), Scott Schlechter (GRI) for sharing the centrifuge tests data. Funding provided by NSF and DFI. 